\title{
LAS ANTÍPODAS DE LA GOBERNANZA AMBIENTAL EN EL TERRITORIO CAMPESINO AGROALIMENTARIO DEL MACIZO COLOMBIANO
}

\section{THE ANTIPODES OF ENVIRONMENTAL GOVERNANCE \\ IN THE AGRICULTURAL FOOD TERRITORY OF COLOMBIAN MASSIF}

\author{
Nicolás Jiménez Iguarán \\ Jorge Andrés Rincón Largo \\ Universidad Nacional Abierta y a Distancia, Colombia \\ Universidad de Manizales, Colombia \\ nicolas.jimenez@unad.edu.co \\ jrincon@umanizales.edu.co
}

\section{RESUMEN}

La gobernanza ambiental consiste en establecer dos vías de intervención territorial diferentes pero complementarias: la vía coercitiva del Estado y la vía reguladora del mercado. Este artículo constituye un intento por comprender una estrategia alternativa de gobernanza que confronta este enfoque $y$, en consecuencia, estas dos vías de intervención. Se trata del Territorio Campesino Agroalimentario del Macizo Colombiano, una propuesta que se ha venido implementando, de facto, en algunas regiones del país, particularmente en varios municipios del norte de Nariño y el sur del Cauca.

Palabras clave: Gobernanza ambiental, Territorio campesino agroalimentario, Macizo Colombiano.

\section{ABSTRACT}

Environmental governance consists of two different but complementary intervention approaches: the coercive way of the state and the regulatory way of the market. This article is an attempt to comprehend an alternative governance strategy that confronts this approach and, consequently, these two forms of intervention. This is about the Agri-food Rural Territory of the Colombian Massif, a strategy that has been implemented, de facto, in various regions of the country, and in several municipalities in the north of Nariño and the south of Cauca in particular.

Keywords: Environmental governance, Agrifood Rural Territory, Colombian Massif. 


\section{INTRODUCCIÓN}

El Consejo Nacional de Política Económica y Social aprobó el 16 de enero de 2018 un documento que define los "lineamientos de política para la construcción e implementación de un modelo de desarrollo regional sostenible en el Macizo colombiano". Conocido como el CONPES 3915, este documento propone un conjunto de estrategias para enfrentar las problemáticas más urgentes relacionadas con la gobernabilidad, la institucionalidad y la estabilidad social, económica y ambiental de la región. Estas problemáticas se sintetizan en tres ejes: i) el deterioro del capital natural, el aumento de la vulnerabilidad ante desastres naturales y el cambio climático; ii) las actividades productivas que afectan la sostenibilidad del territorio y aportan al cambio climático; y iii) la debilidad institucional para generar gobernanza en el territorio, lo que obstaculiza el desarrollo de acciones oportunas, coordinadas y eficientes (DNP, 2018, p. 8).

Desde esta perspectiva, lo que "obstaculiza el desarrollo de acciones oportunas, coordinadas y eficientes" para restaurar el capital natural y resolver los conflictos socioambientales, es "la multiplicidad de actores con diversos intereses" y "su escasa articulación" (Ibíd., p. 70). Ante esto, el documento expone la necesidad de construir una "visión compartida del territorio" capaz de propiciar "un sano equilibrio entre el Estado, la sociedad civil y el mercado" (Ibíd., p. 24). La ausencia de articulación se presenta, entonces, como una de las principales causas de las problemáticas y conflictos que tiene la región del Macizo colombiano.

Sin embargo, este discurso contrasta con las interpretaciones que realizan algunos sectores y grupos sociales del Macizo colombiano para quienes la escasa articulación se debe, más bien, a la imposición de una racionalidad política que prioriza los intereses de las empresas extractivas y no de las población que habitan la región. No se trata, entonces, de falta de voluntad política, sino de unos desacuerdos que, por su propia naturaleza, impiden construir una visión compartida del territorio. Tanto a nivel nacional, como en la región maciceña en particular, las consultas populares de los últimos años contra el extractivismo (20132019) ${ }^{1}$, así como las masivas movilizaciones sociales de la última década (Cruz, 2017), ponen en cuestión la tesis de un "sano equilibro" entre los diferentes actores y niveles de gobierno ${ }^{2}$. Esto obliga a repensar el concepto de gobernanza desde sus propios lugares de enunciación y a partir de los límites que ella misma tiende a producir.

Davies (2011) afirma que la gobernanza es una estrategia hegemónica. De acuerdo con esta tesis - que se contrapone a los análisis que generalmente se producen en la academia - la gobernanza es un dispositivo de jerarquización, control y domino que, de forma sutil, tiende a invisibilizar las contradicciones al tiempo que las profundiza. Para el caso del

\footnotetext{
${ }^{1}$ Las comunidades de Piedras (2013) y Cajamarca (2017) en Tolima, de Tauramena (2013) en Casanare, de Cabrera (2017) y Arbeláez (2017) en Cundinamarca, de Pijao (2017) en Quindío y de Sucre (2017) y Jesús María (2017) en Santander, adelantaron consultas populares para frenar proyectos extractivos mineros y de hidrocarburos. Sin embargo, la Corte Constitucional tumbó la ley que le otorgaba a estas consultas el poder de veto. La contundencia de estas consultas populares, particularmente la de Cumaral, Meta, fue lo que detonó las modificaciones jurisprudenciales para limitar la participación ciudadana. Algunos municipios, como San Lorenzo (2018) en Nariño y Mercaderes (2019) en Cauca, realizaron consultas populares autogestionadas sin el apoyo de la Registraduría Nacional. En todos estos casos hubo un rechazo enfático a los proyectos extractivos.

2 Este escenario de gobernanza en el Macizo colombiano fue preparado en 1978, por la UNESCO, cuando esta región fue declarada como Reserva de Biosfera. El carácter experimental de esta figura tiene el propósito de conciliar la protección de los ecosistemas con la amplíación de proyectos productivos en el marco del "desarrollo sostenible". De esta manera, el Macizo colombiano se convierte en una zona de alto valor estratégico y geopolítico a nivel global.
} 
Macizo colombiano, como en muchas otras regiones del planeta, el discurso de la gobernanza parece estar, en efecto, inclinado a favorecer unos intereses por encima de otros. Más que la participación, la debilidad institucional o la falta de articulación, lo que está en juego es una disputa entre formas de pensar, de habitar y de ordenar el territorio, entre las que difícilmente podrá llegar a establecerse un "sano equilibrio" o, como mínimo, una alianza.

En este orden de ideas, la gobernanza puede pensarse como una tecnología de pacificación. Quizás tenga razón Duffield (2001, p. 34. La traducción es nuestra), en que "la actual preocupación de la gobernanza global gira entorno al establecimiento de la paz liberal al interior de sus conflictivas fronteras": evitar o resolver conflictos bélicos de alta intensidad para reestructurar el funcionamiento de la economía de mercado y ampliar la explotación sostenible del capital natural. ¿Es la gobernanza, entonces, un conjunto de prácticas de coordinación y cooperación, como suele afirmarse, o un "caballo de troya" que intensifica y reproduce las contradicciones socioecológicas en los territorios una vez se introduce en ellos?

Teniendo en cuenta estas y otras cuestiones, el presente artículo tiene el propósito de contrastar el proceso de gobernanza ambiental que impulsa el Gobierno nacional, el sector privado y los organismos internacionales en el Macizo colombiano, con una forma de organización ambiental del territorio que se construye a través del proceso conocido como el Territorio Campesino Agroalimentario (TCA) del norte de Nariño y el sur del Cauca.

\section{LA GOBERNANZA AMBIENTAL COMO RACIONALIDAD POLÍTICA}

La gobernanza ambiental es uno de esos tantos conceptos polisémicos que inundan nuestro vocabulario político. Su uso está asociado, casi siempre, a las prácticas de «buen gobierno», o «buena gobernanza», estipuladas por organismos internacionales como el Fondo Monetario Internacional (IMF, 1997), el Banco Mundial (Lateef, 2016), las Naciones Unidas (United Nations, 2014), la Unión Europea (European Commission, 2014), la Organización Mundial del Comercio (Sampson, 2008) o la Organización para la Cooperación y el Desarrollo Económicos (Schuler, 2008). En general, la gobernanza hace referencia a un nueva fase política que se caracteriza por propiciar la creación de "redes" de compromiso, cooperación y coordinación entre los actores sociales. Esa capacidad, casi performativa, de construir redes, le está garantizada por su propia naturaleza o, como mínimo, legitimada. Por eso se valora positivamente que el Estado organice su propia retirada del escenario público porque permite que los demás actores determinen, en un juego relativamente ecuánime, las relaciones sociales, económicas y políticas. En este sentido, la gobernanza puede entenderse como una práctica de gobierno (en tanto actividad) liberada de los excesos y abusos que suele tener el gobierno (en tanto institución). Lo que este concepto viene a indicar, en otras palabras, es que la sociedad civil se está liberando del poder soberano y, por lo tanto, opresor, que sobre ella ejerce el Estado.

Esta concepción de gobernanza da por sentado un relativo equilibrio político e institucional al considerar, a priori, la existencia de una cierta estabilidad social, política, económica, cultural y emocional ${ }^{3}$. De acuerdo con la teoría

\footnotetext{
Richards (2007) realiza una aproximación a la gestión social y a la administración pública desde el concepto de gobernanza emocional, que implica, en pocas palabras, tomar el conocimiento intuitivo que utilizan los medio masivos de información para fortalecer procesos de comunicación emocional y crear marcos cognitivos que permitan promover los principios de la buena gobernanza. El discurso del "terrorismo" es un buen caso
} 
de la gobernanza4, esta estabilidad produce las condiciones para que todas las partes puedan tener las mismas oportunidades y acordar un proyecto común. Desde el punto de vista socioeconómico, la gobernanza no determina los resultados, pero sí permite equilibrar los poderes para que todas las personas tengan la posibilidad de alcanzar un nivel de vida óptimo (Berggruen y Gardels, 2013; Dominguez, 2015; Drobot, 2010; Kooiman, 2003; Stoker, 2019). ¿Qué hace posible este equilibrio? Una economía de mercado que, guiada por el principio del laissez-faire, genera mejores oportunidades de empleo y riqueza. Además, somete al gobierno (léase, el Estado) a los designios de la gente (léase, la sociedad civil), y no al revés. Como señalan Berggruen y Gardels (2013, p. 105. La traducción es nuestra), "la competitividad obliga al gobierno a ser más disciplinado". Por esta razón, la «buena gobernanza» se convierte en el fundamento para una «buena sociedad», y la «buena gobernanza ambiental» en la base para construir una «buena sociedad sostenible». La gobernanza es, entonces, el resultado de un desplazamiento que, desde las formas tradicionales de poder político, produce nuevos estilos de gobierno motivados por la aparición de unas "redes" (governance networks) que permiten que las instituciones estatales y no estatales puedan coordinarse de forma fluida, horizontal y justa 5 .

Para Laval y Dardot (2015, p. 278) "la polisemia del término es una indicación de su uso".

de gobernanza emocional que, como argumenta el autor, tiene la capacidad de crear una suerte de "seguridad ontológica" por medio de las redes que los medios masivos de información, articulados en este tipo de discurso, tejen a modo de una "matriz psicosocial" que absorve la subjetividad. Véanse, para un contraste crítico, las reflexiones de Foucault en Seguridad, Territorio y Población, en particular las clases del 18 y 25 de enero de 1978.

${ }^{4}$ Para un análisis minucioso sobre la evolución teórica y práctica de la gobernanza, véase Beunen et al. (2015). ${ }^{5}$ Como afirma (Rhodes, 2017), las redes son la Primarii Lapidis de la gobernanza.
Un uso que revela dimensiones que generalmente se ocultan bajo el prisma de interpretaciones demasiado ingenuas que consideran que la gobernanza es el resultado lógico de ciertas condiciones materiales y simbólicas. El término proviene del latín gobernantia (siglo XIII) que designa el hecho y el arte de gobernar (Gaudin, 2002). Sin embargo, el uso de este concepto, que coincide, actualmente, con la traducción del término anglosajón "governance", se desdobla en las nociones de soberanía y gobierno. En este sentido, la gobernanza desplaza el principio de soberanía popular para instalar las prácticas de "buena gobernanza" heredadas del management empresarial. La "gobernanza corporativa", es decir, la forma que toma la política interna de las empresas, se convierte, paúlatinamente, en una metáfora de la política al extenderse al dominio de lo público (Brown, 2001). La gobernanza no supone, como suele afirmarse, el retroceso del Estado sino más bien "la transformación de la acción pública, haciendo del Estado una esfera regida, también ella, por reglas de competencia y sometida a exigencias de eficacia semejantes a las que conocen las empresas privadas" (Laval y Dardot, 2015, p. 275). Abordar la gobernaza desde la metafora de las redes contribuye muy poco, por no decir nada, a su comprensión política ${ }^{6}$. Como señala Brown (2001) la gobernanza hace referencia "a aquellas formas de gobierno que no se atreven a llamar «gobierno»". La gobernanza no sería, por lo tanto, una cuestión en sí misma, sino una de las formas que toma el problema del Estado, que, como señala Foucault no es más que "el efecto móvil de un régimen de gubernamentalidades múltiples" (2007, p. 96).

\footnotetext{
Para una análisis crítico sobre la gobernanza, véanse Monedero (2003, 2008), Davies (2011), de Sousa Santos y Garavito (2007) y Jessop (2016). Para una crítica del concepto de "redes de gobernanza", véase Davies (2011, 2014a, 2014b). En lo sucesivo, el artículo toma algunos elementos de estas fuentes.
} 
En este sentido, la gobernanza ambiental vendría a ser una suerte de estratagema para homogenizar, a través de la competencia económica, un proyecto socioecológico específico y una forma de organización territorial concreta. Un régimen gubernamental que, a través de una modalidad específica de administración estatal, produce un cierto tipo de subjetividad. En otras palabras, una racionalidad política (Foucault, 2007). Como afirma Backer, "mientras los actores no gubernamentales ejercen el poder de gobernanza, ninguno de estos sistemas ha logrado alcanzar la velocidad de escape suficiente para alejarse de la orbita del Estado" (2012, p. 89. La traducción es nuestra). Más allá del debate sobre las posibilidades de un gobierno sin Estado (o de una gobernanza sin gobierno como lo plantea Backer), un análisis menos ingenuo sobre la gobernanza delata una práctica de gubernamentalidad 0 , si se quiere, un nuevo modo de gobierno que busca resolver las tensiones entre legitimidad, gubernamentalidad y soberanía?. Como señala Foucault en Nacimiento de la Biopolítica, en "la distinción entre Estado y sociedad civil" es posible ver "una forma de esquematización propia de una tecnología específica de gobierno" (2007, p. 361). Y esto es precisamente lo que oculta la gobernanza: si en un principio la virtud de este desplazamiento era justamente destacar la novedad política de una forma de gobierno en gobernanza (governing as governance $)^{8}$, lo que realmente se revela

Como afirma Monedero, "si la tesis crítica en los años setenta era la legitimidad y la antítesis capitalista la gobernabilidad, en los años noventa la gobernanza se presenta como una falsa síntesis, toda vez que no cuestiona en modo alguno el modelo que generó la protesta" (2008, p. 158). Y Jessop, en esta misma vía, señala que, a principios de los años 60 del siglo XX, las elites nacionales y transnacionales "expresaron una enorme preocupación [...] sobre varios de los problemas que estaban empezando a enfrentar las democracias liberales, como la sobrecarga gubernamental, la crisis de legitimidad y los problemas de ingobernabilidad, situación que condujo a la búsqueda de arreglos políticos y sociales para enfrentarlos" (2016, p. 164. La traducción es nuestra).

8 Véase Kooiman (2003). es que la gobernanza es una forma específica de gobierno (governance as governing) que

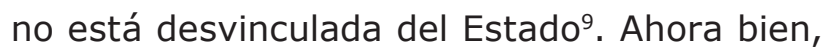
lo que aquí consideramos problemático, no es el inevitable vínculo entre gobernanza y Estado, sino más bien las transformaciones que se producen al interior de este último y sus efectos en la acción pública. Las condiciones sobre las que se fundamenta la gobernanza son, en realidad, los modos en que se expresa la racionalidad neoliberal en su búsqueda por generalizar la competencia como norma de conducta y la empresa como modelo para la acción pública. En términos foucaultianos, la configuración biopolítica que se despliega con la gobernanza, no sólo implica un ejercicio del poder pastoral sobre individuos, sino también, sobre territorios. Es decir, un poder capaz de crear las condiciones adecuadas para que los territorios puedan ser ordenados en clave de "capital natural".

Lo que resulta interesante de la gobernanza es justamente lo que se oculta bajo su tutela, es decir, las contradicciones ${ }^{10}$ que mágicamente cree superadas. Sousa Santos y Garavito aluden, con razón, a "los silencios" de la gobernanza y a la falta de mención de conceptos como "transformación social, participación popular, contrato social, justicia social, relaciones de poder y conflicto social" (2007, p. 36). Algunos autores consideran que no es apropiado aplicar el conceto de gobernanza en otros contextos (Bassols y Mendoza, 2011), pero esa

\footnotetext{
${ }^{9}$ Estamos de acuerdo con Davies en que "las teorías posttradicionales tienen una lectura errada de la supuesta transformación del gobierno en gobernanza". Y que "una tarea central para repensar la gobernanza implica, por lo tanto, determinar por qué 'las redes de gobernanza' no cumplen con las promesas de una 'gobernanza en

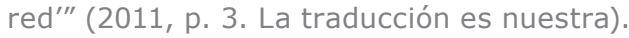

${ }^{10}$ Nos referimos, principalmente, a las dos contradicciones del capital interpretadas desde el marxismo: la contradicción capital-trabajo (Marx, 2014) y la contradicción capital-naturaleza (O'Connor, 1991). Véase, para un análisis más amplio, el libro Diecisiete contradicciones y el fin del capitalismo de David Harvey (2014).
} 
es justamente su función: ser un universal político, una nueva racionalidad gubernamental a nivel global capaz de desplegar "la lógica del mercado como lógica normativa generalizada, desde el Estado hasta lo más íntimo de la subjetividad" (Laval y Dardot, 2015, p. 25). Como vemos, las contradicciones que se creían superadas parecen más bien reforzarse. Por eso el desplazamiento conceptual y político al que alude la gobernanza, más que describir analíticamente un estado de cosas, lo proyecta normativamente. La gobernanza es, en este sentido, una forma de gatopardismo ${ }^{11}$.

Ahora bien, para introducir nuestro análisis, es necesario contar con una definición de gobernanza ambiental que destaque, precisamente, su carácter agonístico y geopolítico. Una definición que permita ubicar, dialécticamente, su función en el marco de los entramados asimétricos de las relaciones de poder que se acumulan dinámica e históricamente en los territorios. La ecología política es, en este orden de ideas, un buen punto de referencia. Según De Castro et al., la gobernanza ambiental es "el proceso de formulación y refutación de imágenes, diseños y ejecución de los procedimientos y prácticas que configuran el acceso, control y uso de los recursos naturales entre actores diferentes" (2015, p. 18). Más allá de la retórica oficial - normativa y maniquea - este concepto también se suele utilizar, en menor medida, para hacer referencia a las disputas políticas

${ }^{11}$ Monedero desarrolla la discusión sobre el Estado en relación con la gobernanza y la globalización en Disfraces del Leviatán. El Estado, señala, "en modo alguno está desapareciendo, sino que, debido principalmente a la debilidad de las clases populares -0 , desde su reverso, a causa de la hegemonía clara y consciente de las élites globalizadas -, se están superando elementos de la forma Estado nacional keynesiano para adaptarlo a la necesidad de una estatalidad funcional al capitalismo globalizado" (2008, p. 60). Como afirma Jessop, el neoliberalismo "disfraza la naturaleza del poder de clase mucho mejor que cuando el aparato de Estado está abiertamente controlado por las clases dominantes o por los gerentes estatales" (2016, p. 211. La traducción es nuestra). que se libran en el terreno de las relaciones socioambientales. Desde esta perspectiva, la gobernanza ambiental está asociada a los modos contemporáneos en que se reorganizan y reconfiguran los procesos de gestión de los «recursos naturales» a distintas escalas y entre actores muy diversos. O, como señala Davies (2011), a las disputas por la hegemonía. Por eso aquí utilizamos la gobernanza, no solo como un concepto (Jessop, 2016; Kooiman, 2003; Ostrom, 2014 ) o como un proceso social (Gabriel, 2014; Robbins \& Luginbuhl, 2007; Rueda, 2012; Weston y Bollier, 2013), sino, y sobre todo, como un escenario explícito de confrontación política y de reproducción semiótico-material de la naturaleza (Davies, 2011, 2014a, 2014b; De Castro et al., 2015; Hogenboom et al., 2012).

\section{CONFLICTO, DESARROLLO Y GOBERNANZA EN EL MACIZO COLOMBIANO}

Teniendo en cuenta estas definiciones es posible ubicar la probemática del Macizo colombiano en clave de gobernanza. Como otras regiones rurales del país y del mundo, la estrella fluvial más grande de Colombia está siendo sometida a un modelo de «ordenamiento» que no está en sintonía con los intereses y anhelos de sus pobladores, y que guarda poca o ninguna coherencia con los reajustes metabólicos que necesita el planeta. Desde la década de los 90 del siglo pasado, esta región ha experimentado un proceso de transformación muy profundo y doloroso que está modificando sustancialmente su geografía física y política. En el Macizo colombiano las lagunas, los cerros, las montañas y los páramos están experimentando cambios geofísicos muy intensos y en algunos casos irreversibles. Asimismo, los pobladores campesinos, indígenas, negros y mestizos de esta región están siendo sometidos a condiciones de 
pobreza, despojo y lumpenización que incuban nuevos conflictos y profundizan la violencia. En efecto, los ríos y tierras del Macizo corren el riesgo de seguir deteriorándose como consecuencia de la presión tecnológica del modelo extractivista que, además, amenaza los sistemas agroecológicos de las comunidades.

De acuerdo con los "Lineamientos de política y estrategias para el Ordenamiento territorial y el desarrollo sostenible del Macizo colombiano (2015-2018)" del Departamento Nacional de Planeación, las principales problemáticas del Macizo están asociadas a la "sostenibilidad ambiental", a las "actividades productivas" y a la "gobernanza multinivel" (DNP, 2015). Pero ¿cuáles son los principales detonantes de estas problemáticas? Para los pobladores, el modelo de ordenamiento territorial, que responde al Plan Nacional de Desarrollo y a sus estrategias transversales de política ${ }^{12}$, es la principal causa.

Contrario al espíritu de descentralización y autonomía consagrado en la Constitución Política de 91 y en la ley 388 de 1997, el modelo económico subordina los procesos de ordenamiento territorial a los planes de desarrollo del Gobierno Nacional. El CONPES 3915, aprobado el 16 de enero de 2018, subordinó el ordenamiento territorial a la estrategia de «crecimiento verde». De entrada, el ordenamiento y la gobernanza del territorio están enraizados en la matriz desarrollista que promueve la inversión, el control territorial por parte del Estado central y la mercantilización de los ecosistemas (DNP, 2018; Mantilla, 2012). Como afirman de Sousa Santos y Garavito, la globalización neoliberal "no le quitó al Estado su centralidad, sino que, en lugar de ello, lo reorientó para que fuera más útil a los intereses del capital global" (2007, p. 24).
Este modelo de organización del territorio impone un orden que tiende a desconocer, excluir y criminalizar otros modelos como los Resguardos Indígenas, las Zonas de Reserva Campesina o los Territorios Campesinos Agroalimentarios, por nombrar solo algunos. El ordenamiento territorial promovido por el Gobierno funciona como un mecanismo geopolítico que intensifica los conflictos por el uso, la distribución y la apropiación de los bienes comunes o vitales ${ }^{13}$. Incluso en los casos donde la misma ley ampara la autonomía territorial, como en los Resguardos Indígenas, los Territorios Ancestrales o los Territorios Colectivos Afrocolombianos, no dejan de presentarse conflictos como consecuencia de las huellas que van dejando las locomotoras del desarroIlo, una metáfora perversa pero muy apropiada para describir la forma en que opera la gobernanza en colombia ${ }^{14}$.

Ahora bien, para el campesinado colombiano el problema es mucho más complejo debido a que el modelo de desarrollo rural no lo reconoce como sujeto político. Hoy en día el campesinado carece de las herramientas jurídicas necesarias para proteger sus derechos frente a un modelo de desarrollo basado en un reordenamiento de los territorios que favorece los intereses del capital en detrimento de las economías locales. De ahí que el ordenamiento territorial en Colombia sea un escenario de disputa permanente, no sólo por los medios técnicos e ideológicos para su producción y reproducción, sino por el sentido mismo de su función pública.

\footnotetext{
${ }^{13}$ De ahora en adelante utilizaremos el concepto de bienes comunes o bienes vitales, salvo que sea pertinente utilizar otras acepciones. Véase Mattei (2013).

${ }^{14}$ Como señala Mantilla, "no es una metáfora inocente la usada por el Gobierno Santos para hablar de su plan económico. La locomotora es la imagen por excelencia para mostrar la ideología de progreso, la máquina que vence la naturaleza, que no tiene reversa, que transporta mercancías y personas, y que se mueve con regularidad" (2012, p. 12).
} 
Bebbington e Hinojosa (2007) identifican cinco campos temáticos bastante útiles para entender la lógica actual de los procesos de ordenamiento territorial y gobernanza. Estos campos introducen unas condiciones materiales y simbólicas que profundizan las contradicciones y que la teoría de la gobernanza siempre aborda a través de rodeos. El primero de ellos es la neoliberalización, que supone un rediseño institucional para modificar los derechos de acceso y control de los bienes comunes. En segundo lugar, y como complemento del anterior, está la transnacionalización de la economía y de la política donde los actores globales se introducen en territorios locales modificándolos de múltiples maneras. El siguiente campo temático es el de la movilización social que emerge como consecuencia de los dos anteriores. Este campo permite reconocer los procesos de acción colectiva encaminados a contrarrestar las formas en que la neoliberalización y la transnacionalización configuran el territorio rural.

Ahora bien, la intensidad con que se desarrollan los procesos extractivos genera las condiciones para un cuarto campo temático: el de la desintegración de las estructuras sociales locales, sus costumbres, sus formas de gobierno y sus economías propias. El siguiente y último campo es el de la reterritorialización, que tiene lugar cuando se logra configurar un «orden» territorial determinado por la correlación de fuerzas. Hoy el proceso de reconfiguración territorial en el país está generando profundas transformaciones ecosistémicas y sociales. El Estado y el mercado, que son los que, en últimas, lideran los procesos de gobernanza, tienen la capacidad de "producir estructuras nacionales con territorios locales incorporados a circuitos económicos internacionales" (Bebbington e Hinojosa, 2007, p. 303).

Ahora bien, los esquemas de gobernanza ambiental suelen enfocarse en los dos primeros campos a través de la proliferación de marcos internacionales en materia de medio ambiente, de la intervención y transformación estatal, y del incentivo para la cooperación internacional. Esto explica, en buena parte, por qué la política ambiental en Colombia es disfuncional y por qué ha conducido a la consolidación de un proceso de ordenamiento territorial que deteriora la naturaleza y el tejido sociall ${ }^{15}$. Ante esta realidad, surge la necesidad de producir otras formas de reterritorialización sobre la base de la protección y dignificación de la vida en todas sus formas.

Es importante aclarar, en todo caso, que la gobernanza ambiental no es únicamente una estrategia retórica. Desde la ecología política latinoamericana lo que se constata es la introducción de otras lógicas de gobierno tendientes a desarticular los procesos endógenos de organización política. Esto coadyuva, entre otras cosas, a potenciar los procesos de transformación del Estado, especialmente en Colombia y América Latina, donde la gobernanza no encuentra los mismos factores que propiciaron su aparición.

\section{EL GIRO ECO-TERRITORIAL EN EL MACIZO COLOMBIANO}

...hemos seguido los pasos de los pueblos indígenas

Robert Daza, Líder Campesino del CIMA

El Macizo colombiano se extiende por $89 \mathrm{mu}-$ nicipios en los departamentos de Nariño, Putumayo, Huila, Cauca, Caquetá, Tolima y Valle. En Cauca y Nariño, donde se está implementando

\footnotetext{
${ }^{15}$ Como señalan Guhl Nannetti y Leiva (2015, p. 32), nos encontramos en un nuevo paradigma del desarrollo "en el que el medio ambiente sano deja de entenderse como un límite racional a los impactos de las actividades del desarrollo y se convierte en un espacio para la gestión del sector privado y la realización de negocios".
} 
el Territorio Campesino Agroalimentario, se concentran, respectivamente, el $25 \%$ y el $14 \%$ de los 481 títulos mineros que tiene esta región. Hay al menos 134 permisos para exploración minera de los cuales ya se han otorgado más de 4 títulos a las empresas Anglo Gold Ashanty y Gran Colombia Gold (Duarte, 2017; DNP, 2018). Los títulos y solicitudes en el territorio muestran el cruce entre distintas territorialidades: unas de carácter popular, campesino, indígena y agroalimentario que entran en conflicto con otras de carácter corporativo, extractivo y desarrollista. Empresas como Continental Gold, Anglo Gold, Carbo Andes, entre otras, acaparan más de 30.000 hectáreas de tierra para proyectos extractivos a gran escala (Mantilla, 2017; Agencia Prensa Rural, 13 de julio de 2017).

Estos proyectos están amenazando la vida campesina de la región donde prevalece el minifundio (de máximo 4 hectáreas) para el desarrollo de actividades principalmente agrícolas. El Macizo colombiano ha perdido más de 500.000 mil hectáreas de bosques a causa de las actividades agroindustriales y mineras (IGAC, 2015). Por esta razón, las comunidades campesinas de la región han tenido que confrontar la penetración violenta del capital, principalmente transnacional. Y si esto las ha llevado a generar ciertos niveles de inestabilidad política e institucional, o a rechazar los pactos que proponen el Estado y las empresas, no es precisamente por capricho. Se trata de un conflicto entre dos modelos de gobernar y organizar el territorio donde se pone en juego la vida misma.

Algunas autoridades locales del Macizo, como Miller Eloy Muñoz, exalcalde de Villanueva, Nariño (2016-2109), han sido enfáticas en recordarle a la Agencia Nacional de Licencias Ambientales (ANLA) y a la Agencia Nacional de Tierras (ANT) que la comunidad no está de acuerdo con las concesiones mineras en el territorio. Frente a la grave situación ecológica y humanitaria que vive la región, las comunidades han tenido que repensar la región, o como diría Noguera (2004), repoetizar y reconstruir su mundo. Con el propósito de neutralizar esa racionalidad, extractivista y desarrollista, las comunidades insisten en la construcción desde lo local, en la adopción de marcos cognitivos biocéntricos y en la articulación de las luchas populares por la justicia social y ecológica. En este proceso se hace visible, constantemente, la contradicción entre gobernanza y soberanía que mencionamos anteriormente.

La llegada de las empresas transnacionales de minería a la región, el narcotráfico y las dinámicas del conflicto armado, han provocado fuertes tensiones, no sólo por las alteraciones que han sufrido los ecosistemas, sino también por los cambios que han provocado en la geografía política ${ }^{16}$. Desde 1975 hasta el día de hoy, ha habido un ascenso significativo de las luchas socioecológicas en el Macizo, particularmente en el norte de Nariño y el sur del Cauca. Dentro de las reivindicaciones principales se encuentran: el rechazo a la industrialización de la agricultura, la exigencia de reformas a la política agraria para favorecer al mediano y pequeño productor, el respeto a la soberanía territorial y alimentaria, el pago cumplido de salarios a médicos y enfermeras y la suspensión de proyectos mineros (García, 2017, p. 9).

Para las comunidades maciceñas, este modelo de desarrollo es una estrategia para territorializar las políticas económicas neoliberales y propiciar la inversión extranjera por medio de la regionalización, los planes de consolidación

\footnotetext{
${ }^{16}$ El 5 de diciembre de 2011, organizaciones campesinas de la región denunciaron que "la empresa Gran Colombia Gold, con el apoyo del Gobierno Nacional, llegó a San Lorenzo y Arboleda a fabricar un conflicto que no había" (REDHER).
} 
y la mercantilización de los ecosistemas (Mantilla, 2012, p. 15-18). Esta estrategia de territorialización tiene como consecuencia la desterritorialización del campesinado como sujeto político. En tanto discurso, el desarrollo "termina transversalizando todas las dimensiones de la vida, surgiendo como principio rector una lógica lineal donde no queda espacio para la diferencia" (Rincón, 2012, p. 64). El actual desconocimiento del campesinado como sujeto de derechos colectivos impide que se le reconozca su derecho individual y colectivo a la tierra, a sus formas autónomas de construir el territorio y al establecimiento obligatorio de mecanismos de participación (CastiIla, 2016). Pero el orden que buscan imponer las empresas mineras, los organismos económicos internacionales, las instituciones del Estado y los actores armados, no solo pretende modificar sustancialmente el metabolismo socioeconómico de la región, generando condiciones de desigualdad social e inseguridad alimentaria, sino también la propia subjetividad política de la comunidad.

Con el TCA las comunidades del norte de $\mathrm{Na}-$ riño y el sur del Cauca construyen un proceso de organización ambiental del territorio que articula la lucha por la justicia ambiental (derechos humanos) con la lucha por la justicia ecológica (derechos de la naturaleza) (Rincón, 2017, 2017a; Cruz, 2017a). La imposición del modelo de desarrollo capitalista ha incitado nuevas formas de participación y movilización social que focalizan sus esfuerzos en la defensa de lo común y de los derechos humanos en un contexto de violencia socioeconómica muy intenso. Estamos ante un caso de ambientalización de las luchas indígenas y campesinas (Leff, 2003, p. 37-38); o lo que Svampa (2012, p. 190) denomina, un giro eco-territorial "que da cuenta cada vez más del cruce innovador entre matriz indígena-comunitario y el discurso ambientalista".
Durante sus tres décadas de lucha, el Comité de Integración del Macizo Colombiano (CIMA) ha ido introduciendo en la región la temática ambiental a través de la lucha por el reconocimiento del campesinado como sujeto político y la configuración de un pensamiento agroambiental que desafía los esquemas desarrollistas, antropocéntricos y patriarcales del modelo hegemónico. Como podrá apreciarse más adelante, lo agroambiental cumple un papel muy importante en la configuración del TCA, ya que determina su carácter articulador y su función protectora (Duarte, 2017).

\section{LA GOBERNANZA AMBIENTAL EN EL TERRITORIO CAMPESINO AGROALIMENTARIO}

iCuando las transnacionales mineras amenazaron con llevarse el agua, reaccionamos!

Amanda Martínez

Lideresa Campesina del Macizo

Si los movimientos de oposición quieren ser algo más que estrellas fugaces que se consumen cual fogonazos en el cielo nocturno, tendrán que propugnar un proyecto bastante integral de lo que debería implantarse en lugar de nuestro deteriorado sistema, así como estrategias políticas serias para alcanzar esos objetivos.

Naomi Klein Esto lo cambia todo: el capitalismo contra el clima

Aunque la gobernanza ambiental tenga la apariencia de una red conformada por interacciones horizontales entre los diferentes actores sociales para gestionar ambientalmente el territorio, desde una mirada crítica surgen otros elementos que suelen ocultarse bajo la retórica del discurso hegemónico. Por eso resulta apropiado utilizar, en adelante, la definición de De Castro et al., según la cual la gobernanza 
ambiental es, más bien, "el proceso de formulación y refutación de imágenes, diseños y ejecución de los procedimientos y prácticas que configuran el acceso, control y uso de los recursos naturales entre actores diferentes" (2015, p. 18). Entendida de este modo, la gobernanza ambiental hace referencia a la configuración de un espacio político donde se disputan las diferentes estrategias para ordenar ambientalmente el territorio. Por eso el TCA es un proceso que instala mecanismos de participación popular, pero que propende también por instancias de decisión jerárquicas que garanticen el control y la protección del territorio. Solo en clave de "control territorial" es posible afirmar que el TCA es un proceso de gobernanza ambiental:

Cuando decimos control territorial, estamos hablando entonces de cerrarle filas a las multinacionales para el extractivismo, porque estos territorios que hoy pensamos configurar como Zonas de Reserva o como Territorios Campesinos Agroalimentarios son los más solicitados por multinacionales para minería (CNMH y FUNDESUMA, 2017: 483).

Esta es una de las razones por las cuales el TCA es una amenaza para el establishment. No solo pone en cuestión el supuesto de un "sano equilibrio entre el Estado, la sociedad civil y el mercado", sino que además profundiza sus contradicciones. No cabe duda de que la represión, persecución y estigmatización del movimiento social, ambiental y popular se debe, justamente, al avance que han tenido las comunidades en materia organizativa y al contrapeso que han hecho a los esfuerzos de la gobernanza neoliberal por llenar los vacíos que ha producido la violencia estructural. En entrevista con Desde Abajo, Víctor Collazos, líder regional del CIMA, señala lo siguiente, a propósito de la muerte de cuatro indígenas y tres campesinos en Cauca y Nariño durante el mes de agosto de 2016:

Durante el tiempo de la campaña, había una posición muy férrea de la organización comunitaria por construir planes de vida desde las localidades y por la defensa del territorio Se había hecho un foro grande y en el foro se había determinado que el territorio de Almaguer era para que la gente conviviera, para sembrar alimentos y para cuidar el agua y la diversidad del medio ambiente. Había cierta oposición comunitaria a la minería por el grado de contaminación que genera la minería ilegal, aunque Almaguer está siendo solicitado también por la minería transnacional. Entonces miramos ese proceso electoral cruzado por presión de grupos armados y por todo lo de la minería que se impidió en defensa del territorio y del medio ambiente, y por eso creemos que en alguna medida éstas son circunstancias determinantes de estas muertes (Bolívar, 2016).

El asesinato, persecución y criminalización son algunas de las estrategias usadas para acabar con las comunidades y sus protocolos sociales de ordenación del territorio. Las comunidades campesinas de la región del norte de Nariño y el sur del Cauca han tenido que resistir la penetración violenta del capital extranjero en su territorio. Sin embargo, han utilizado esta situación para repensar su territorio, sus relaciones políticas y en general, su propia existencia. Como diría Álvaro García Linera, se produjo una tensión creativa que ha dado origen a un quehacer político en el que las capacidades individuales y colectivas se orientan hacia la construcción de valores y prácticas transformadoras del territorio.

Esta creatividad es la respuesta política a una forma de organizar el territorio que está en 
contradicción con la vida misma y que requiere, sin lugar a dudas, de soluciones radicales y profundas en diferentes dimensiones: epistémicas, sociales, políticas, culturales, tecnológicas y económicas. Como lo han manifestado las diferentes organizaciones que hacen parte de la Cumbre Agraria:

El país necesita un proceso de Ordenamiento Territorial donde sean las comunidades quienes redefinan la manera como se organiza la producción, se distribuye el uso del suelo, se gobierna el subsuelo, y se protegen el aire, el agua, los ecosistemas estratégicos y los medios de vida de las comunidades agrarias. Ese ordenamiento apuntará a armonizar la conservación del medio natural con el aprovechamiento para la pervivencia de las comunidades agrarias (Cumbre Agraria, 2014).

Este mandato colectivo ha sido asumido con creatividad, organización y compromiso por las comunidades del norte de Nariño y el sur del Cauca que construyen Territorio Campesino Agroalimentario. La disputa consiste, entonces, en refutar y reformular colectivamente las prácticas que configuran el acceso, control y uso de los bienes comunes en el marco de las contradicciones que produce el modelo de desarrollo capitalista. Es decir, en confrontar la racionalidad política propia del neoliberalismo que se intenta introducir por medio de los esquemas dominantes de gobernanza. Como fue reconocido por la Agenda Común para la Paz desde los Territorios:

Estas luchas han dado origen a una discusión en torno a lo común, entendido en un sentido educativo como la capacidad de salir de la comprensión clásica de lo gremial y lo político e ir más allá del diálogo de saberes para construir negociaciones interculturales entre los actores sociales populares, de tal manera que sea posible definir estrategias de organización y trabajo que representen una salida del antropocentrismo y androcentrismo hacia el biocentrismo y el Buen Vivir - Vivir Bien y se conviertan en factores fundamentales de unidad, articuladores de agendas y constructores de las nuevas formas de los movimientos sociales (Mejía, 2017, p. 13).

Las luchas sociales no sólo tienen el propósito de abrir espacios de negociación: buscan también afirmar la legitimidad de sus territorialidades, de sus acuerdos, de sus formas de vida. Como el Estado, en su forma actual, carece de voluntad para intervenir en conflictos sociales $y$ atender las demandas de las poblaciones excluidas, no basta con exigir y negociar, es menester desplegar todo un proyecto territorial de «nueva hegemonía» que reivindique otros significados, otros sentidos, otras relaciones socioambientales y otros diseños productivos que garanticen la defensa y protección de los bienes comunes. Como afirma Duby Ordoñez, lideresa campesina del TCA en el Macizo colombiano y habitante de San Pablo, Nariño, "la construcción de territorio tiene que contar con todos y todas, y los gobiernos tendrán el deber y la obligación moral de recogerse en esa ruta"17. Pero mientras el Gobierno no asuma esa obligación moral, la protesta social continuará siendo uno de los mecanismos más efectivos para proteger los territorios.

Esta es una de las diferencias entre la gobernanza y los procesos de autonomía y soberanía territorial: la primera surge para negar e invisibilizar el conflicto, mientras que los segundos para afirmarlo y superarlo. Las comunidades saben que deben ir mucho más allá de la negociación, de lo contrario el proceso

17 Entrevista. Archivo personal, Vereda Alto Llano, San Pablo, Nariño, 14 de diciembre de 2016. 
puede quedar enredado en las redes de gobernanza que el modelo hegemónico de desarrollo ha creado para mantener el statu quo ${ }^{18}$. La gobernanza ambiental que se lleva a cabo desde el Territorio Campesino Agroalimentario se convierte en una «geopolítica de la resistencia», en la medida en que "las comunidades participan de las rivalidades de poder en los territorios que habitan y que son asediados por otros actores geopolíticos" (Portillo, 2016).

En Colombia la protesta social, así como los actos de sabotaje popular, no son solo mecanismos de presión para abrir procesos de negociación, son también acontecimientos que provocan rupturas que potencialmente pueden subvertir el orden establecido. Las protestas pueden instalar instancias de gobierno a futuro solo si sus protagonistas son capaces de construir poder e instituirse como autoridad territorial. De esta manera, soberanía y gobierno hacen parte de un mismo proceso. El caso de las Rosas, Cauca, en 1991, ilustra muy bien este punto. Frente a la negativa del Gobierno de atender a las necesidades de la población maciceña, la comunidad organizó un paro en la Panamericana que obligó al Gobierno a sentarse a negociar. Este hecho político activó procesos de articulación que permanecen vigentes hasta el día de hoy y que han sido mucho más importantes que los propios escenarios formales de negociación que llegaron a generar (Rincón, 2017) ${ }^{19}$.

${ }^{18}$ El concepto de "red" es el que permite realizar las modificaciones semiológicas para desplazar los conceptos que tienden a problematizar el orden social: "resolución de problemas" en vez de "transformaciones sociales"; "participación de los interesados" en vez de "participación popular"; "auto-regulación" en vez de "contrato social"; "juego de suma positiva" y "políticas compensatorias" en vez de "justicia social"; en vez de "relaciones de poder", "coordinación". En definitiva, "cohesión social y estabilidad" donde ayer se primaba la idea de "conflicto social" (Monedero, 2008, p. 158).

${ }^{19}$ Otro ejemplo, son las propuestas de articulación que se forjaron en el marco la Cumbre Agraria, Campesina,
Para finalizar este apartado, es importante hacer una breve reflexión sobre la dimensión temporal en los procesos de gobernanza. Mientras que la gobernanza funciona a corto plazo, porque responde a la visión cortoplacista de la acumulación de capital, las modalidades de gobierno de los procesos de autonomía y soberanía del Territorio Campesino Agroalimentario se proyectan a largo plazo, en la medida en que se enmarcan en los procesos orgánicos de la vida. Tiene razón Riechmann cuando afirma que "la sustentabilidad puede pensarse como una nueva relación con el tiempo" (2011, p. 134). La temporalidad de la gobernanza es una temporalidad de la gestión eficiente, es decir, económica, de los recursos naturales, mientras que la temporalidad agroalimentaria/agroambiental está orientada por un conjunto de relaciones y disposiciones muy complejas entre los elementos humanos y no humanos que componen el territorio. Cuando se reconoce la finitud de la naturaleza y su relación con la dimensión temporal de las interacciones socioecológicas, se comprende que los cambios que se proyectan para superar el desfase deben ser superiores a los que lo generaron.

\section{EL AGUA COMO PRINCIPIO ORGANIZADOR DEL TERRITORIO}

El agua es un principio ordenador del territorio, por lo que mandatamos una verdadera soberanía territorial donde las comunidades ejerzan su gobierno propio sobre las fuentes hídricas y recuperen las tierras originarias arrebatadas. Mandatamos que se reconozcan las comunidades

Étnica y Popular como resultado de las protestas que se llevaron a cabo entre el 19 de agosto y el 12 de septiembre de 2013. A pesar del incumplimiento del gobierno de Juan Manuel Santos, continúa madurando una apuesta de organización territorial coherente con los reajustes metabólicos que necesita el planeta y con el anhelo de justicia social al que aspiran las comunidades. 
y organizaciones legítimamente constituidas como autoridad ambiental, social y comunitaria, sujetos activos en la construcción y puesta en práctica de las normas y mandatos sociales.

\section{Mandato "En materia de agua" del Congreso Nacional de Tierras, Territorios y Soberanías}

La riqueza del Territorio Campesino Agroalimentario está en su dinámica organizativa y en su horizonte estratégico. Por un lado, porque está configurando todo un poder político y simbólico para expulsar a las multinacionales del territorio y para impedir el avance agresivo de la racionalidad neoliberal. EI TCA ha sido capaz de articular a la comunidad, organizada y no organizada, en la construcción de un metabolismo socioeconómico basado en el principio agroalimentario/agroambienta/20. Por el otro, porque constituye una apuesta novedosa por una organización ambiental del territorio mediante un instrumento de planeación autónomo conocido como el Plan de Vida, Agua y Dignidad (PVAD).

Este plan de vida es un conjunto de propósitos, políticas, objetivos y estrategias comunitarias para el gobierno de los bienes comunes (CNA, 2015; Cuenca, 2017). Los autores de este plan son las propias comunidades que, al margen de los discursos dominantes, viven en permanente diálogo construyendo los lenguajes de

\footnotetext{
${ }^{20}$ Para el caso del Macizo colombiano, ha venido tomando forma un Marco Cognitivo Agroambiental impulsado, principalmente, por el Comité de Integración del Macizo Colombiano - CIMA - y el Coordinador Nacional Agrario. Para la comprensión del este Marco Cognitivo, recomendamos consultar los dos tomos del libro Crecer como un río. Jornaliando cuesta arriba por vida digna, integración regional y desarrollo propio del Macizo Colombiano (Rincón, 2017, 2017a), y la tesis de maestría de William Bernardo Macías Orozco, "Configuración, dinámica y elementos del Marco Normativo Agroambiental del Comité de Integración del Macizo Colombiano - CIMA" (Macías, 2016).
}

valoración con los que interpretan y transforman su territorio. El lenguaje de la comunidad maciceña es el reflejo de un saber contraexperto (Svampa, 2012), contrahegemónico (de Sousa Santos y Garavito, 2007) y decoIonizado (Castro-Gómez y Grosfoguel, 2007), que visibiliza aquello que los lenguajes de valoración monetaria quieren silenciar: transformación social, conflicto, participación popular, crisis civilizatoria, revolución, justicia, lucha de clases, relaciones de poder, protesta social, organización política, cultura campesina, sistemas agroalimentarios, madre tierra, buen vivir, mejor estar, bienes comunes, entre otros. Sin embargo, esto no quiere decir que estas organizaciones estén exentas de incoherencias y contradicciones, pues a su interior se reproducen también dinámicas que están bastante alejadas de los ideales políticos. Son, en otras palabras, procesos dinámicos y heterogéneos marcados por una conflictividad que es inherente a la propia vida; conflictividad que, para la gobernanza, resulta demasiado incómoda.

El plan de vida con el que se construye el TCA tiene cinco ejes: un eje de identidad, relacionado con la memoria viva de la comunidad, sus saberes y su cultura propia; un eje de territorio, relacionado con el espacio en el cual se satisfacen las necesidades vitales y espirituales de la comunidad; un eje de organización social, que hace referencia a los procesos organizativos orientados por intereses comunes; un eje de producción agroalimentaria/agroambiental, que tiene que ver con las actividades productivas orientadas a fortalecer la soberanía alimentaria, la economía solidaria y las relaciones no instrumentales con el medio ambiente; y finalmente, un eje de ordenamiento territorial propio. Como puede observarse, el PVAD es una ruta de acción para una gestión comunitaria del territorio. 
Que el primer mandato del PVAD sea sobre el agua no es una casualidad. El Macizo es el centro de la red hidrográfica de Colombia y cuenta con 65 cuerpos lagunares responsables del nacimiento de los ríos Magdalena, Cauca, Patía, Caquetá, Putumayo y Saldaña. Los nombres con los que se conoce esta región destacan la importancia de este bien común: la Estrella Fluvial de Colombia, el Nudo de Almaguer, la Esponja Hídrica de Colombia y la fábrica de agua del país, entre otros.

Con el pasar de los días, las comunidades han ido notando una intensa disminución del agua como resultado de prácticas antrópicas que disminuyen la cobertura vegetal produciendo disminución de caudales y pérdida de agua por escorrentía y evaporación. Asimismo, la contaminación que causan los pobladores y las empresas está amenazando este importante bien vital. La minería ha sido, en todo caso, su principal amenaza y el detonante de una conciencia generalizada sobre la importancia de su protección (Garay, 2014). Alrededor de este bien común y vital han ido surgiendo múltiples conflictos. Como ya se ha constatado, estos conflictos son el resultado de posiciones antagónicas entre diferentes formas de comprender el territorio.

El choque entre ambas perspectivas ha generado un conflicto muy fuerte en la región por el control del agua. Las autoridades ambientales, por ejemplo, no sólo han sido incompetentes, sino que han contribuido a profundizar el modelo extractivo y privatizador en la región. A pesar de la creación del Ministerio del Medio Ambiente y del Sistema Nacional Ambiental en 1993, se crearon diversos planes, entidades y estrategias como las Corporaciones Autónomas Regionales, los Planes de Ordenamiento y Manejo de las Cuencas Hidrográficas, el Viceministerio de Agua y Saneamiento, los Planes Departamentales de Agua y la Autoridad Nacional de Licencias Ambientales. Para el caso del
Macizo colombiano se creó el Sistema Regional de Áreas Protegidas del Macizo (SIRAP Macizo) pero los resultados no han sido los esperados. Los campesinos y campesinas no confían en la voluntad de las autoridades ambientales. La gobernanza que estas han ejercicio no recoge los sentires de las comunidades.

En el año 2017 se hundió un proyecto de Acto Legislativo que pretendía elevar como norma constitucional del derecho fundamental al agua en directa oposición a las políticas neoliberales del Banco Mundial acogidas por el Gobierno nacional. El debate sobre cómo se entiende este bien común refleja los diferentes mecanismos que lo amenazan. El problema del agua en el Macizo es bastante complejo, involucra a diversos actores y se expresa de diferentes maneras. Lo que es importante destacar en el marco de este artículo es la tendencia a privatizar este bien conforme acuerdos y tratados comerciales. Los Planes Departamentales de Agua, y sus esquemas de gobernanza, han sido los canales principales a través de los cuales se está territorializando esta política. Por eso para las comunidades, principalmente para el movimiento social campesino de la región, hay una necesidad de construir una legalidad local, regional y nacional subalterna, como plantean De Sousa Santos y Garavito (2007). José Leonardo Molina Muñoz, vocero de la Mesa Departamental Agraria en Nariño, explica esto de la siguiente manera:

En lo local estamos tratando de vincular a las autoridades municipales. Nosotros le damos participación, a través de las diferentes asambleas que organizamos en la región, a los alcaldes, a la UMATA, a las entidades ambientales como la CRC y CORPONARIÑO, y les hacemos saber a ellos qué es lo que estamos haciendo y en qué estamos trabajando. Nuestro sueño es construir un territorio agroalimentario acá 
en el norte de Nariño y sur del Cauca. Para eso los estamos vinculando, aunque algunos hacen caso omiso. Hay otros que sí están dispuestos a colaborar en este ejercicio, están con nosotros y nos apoyan. Ellos están entendiendo que, si siguen trabajando solos, nunca van a poder salir adelante; ellos tienen que trabajar con nosotros, con los campesinos, para poder construir la región que todos queremos ${ }^{21}$.

A diferencia del discurso dominante de gobernanza, la legalidad aquí no es el resultado de un consenso, sino de una disputa abiertamente política. Hay un aprendizaje permanente, un diálogo de saberes, un intercambio para aprender a ser gobierno y autoridad en el territorio entre los pobladores. Pero en el intercambio con las autoridades estatales, o con las empresas, los campesinos y campesinas son autoridad. El territorio es, en este orden de ideas, una propuesta político-comunitaria que transita hacia lo político-institucional. Como señalan Granados y Houghton, "la disputa central de las comunidades y organizaciones de base con el Estado y el mercado tiene que ver con la imposición [...] de una «territorialidad corporativa» que expropia el derecho a decidir, al tiempo que expropia los recursos, al vaciar de contenido las democracias liberales" (2017, p. 14).

En el marco de la construcción del TCA en el norte de Nariño y el sur del Cauca, queda claro que para defender los bienes comunes y vitales no basta con ganar capacidad organizativa: es necesario crear los organismos y las instituciones adecuadas para fortalecer el gobierno y la soberanía locales. Una gobernanza ambiental implica, de este modo, un tránsito organizado desde la resistencia activa hacia la construcción de propuestas capaces de organizar el

\footnotetext{
${ }^{21}$ Archivo personal, Entrevista realizada en el Encuentro de Autoridades Campesinas del norte de Nariño y el sur del Cauca en Colón-Génova, 7 de mayo de 2017.
}

territorio de acuerdo con los mandatos construidos por las propias comunidades. El agua ha sido, en el caso del Macizo, el detonante de ese tránsito, ya que desató una potencia creadora muy importante que movilizó a la comunidad. Al igual que en otras regiones del país, en el Macizo las autoridades han demostrado ser incapaces de gestionar de manera "sustentable" el agua. Esto lo han denunciado ampliamente las organizaciones comunitarias. Como lo señaló Duby Ordóñez en el II Encuentro de Autoridades del Territorio Campesino Agroalimentario en Colón-Génova, Nariño el 7 de mayo de 2017:

El Plan de Vida, Agua y Dignidad orienta que en 10 años debe haber un plan coherente de gestión ambiental comunitaria, con indicadores sociales y ambientales fuertes, garantizando la oferta sustentable de buenos servicios ambientales. Señala que el agua es de la gente y no de las empresas privadas y recuerda que la región debe avanzar en un ejercicio de administración pública/ comunitaria en estos temas. El eje principal de integración y gestión ambiental en el territorio es el manejo comunitario del agua ${ }^{22}$.

\section{PALABRAS FINALES:}

\section{IOMNIA SUNT COMMUNIA!}

[La gobernanza es] un concepto nacido para regular, para disciplinar y ocultar el conflicto que atraviesa a las sociedades occidentales (estatistas, capitalistas, modernas), pero que deja abiertas puertas -si bien pocas y estrechas - para convertirlo en un concepto emancipatorio.

Juan Carlos Monedero

El gobierno de las palabras 
Yo creo que el desafío que hacemos al sistema, al modelo, es en el sentido de que nosotros nos empoderamos; la idea es empoderarse, ser gobierno en nuestros territorios y determinar lo que nosotros queremos hacer en ellos. Entonces cuando hacemos el Plan de Vida, su sentido es totalmente opuesto al extractivismo, porque nosotros queremos la vida, queremos la agricultura, queremos la alimentación, queremos los bienes vitales como el agua. El neoliberalismo no ve esto, ellos ven solamente la ganancia, extraer los minerales para exportarlos, mientras que nosotros, por el contrario, defendemos es la vida: esa es la forma de confrontar el modelo neoliberal.

Robert Elio Delgado Líder campesino del CIMA

Es común que, contra toda evidencia, los diagnósticos de coyuntura y contexto anuncien condiciones más democráticas y más apropiadas para la disputa política. Para algunos, el siglo XXI es el siglo de la paz y del fin de los conflictos (o de la posibilidad de tramitarlos por medios no violentos). Una mirada a las prácticas contemporáneas de genocidio revela todo lo contrario (Feierstein, 2014). Ni los procesos de paz del siglo XX y XXI, ni la instauración de gobiernos progresistas en América Latina durante las últimas dos décadas, pueden tomarse como instancias de una apertura democrática en el continente y en el mundo. Como señalan Laval y Dardot (2015, p. 29), "el profundo error cometido por quienes anunciaron la «muerte del liberalismo» fue confundir la representación ideológica que acompaña la instauración de las políticas neoliberales con la normatividad práctica que caracteriza propiamente al neoliberalismo". Es cierto que el vocabulario político cambia (tanto en la derecha como en la izquierda), pero este no se corresponde necesariamente con los procesos socio-políticos que estamos viviendo. No estamos, precisamente, entrando en un periodo de 'larga paz' (the long peace) como señala Steven Pinkard ${ }^{23}$.

La política ambiental en Colombia ha conducido a la consolidación de un modelo de gobernanza orientado por políticas neoliberales. Estas políticas están encaminadas, exclusivamente, a ordenar los territorios en función del crecimiento económico. Como consecuencia, se ha impuesto un patrón de gobernanza que pasa por alto los acuerdos locales con la pretensión de reemplazarlos por "acuerdos" funcionales a la privatización y mercantilización de los ecosistemas, so pretexto del desarrollo sostenible. La gobernanza neoliberal despoja a las comunidades de sus medios de vida y deteriora sus mecanismos de participación para apropiarse de sus bienes comunes. Con esta modalidad de gobernanza, la política y la economía quedan sustraídas y separadas de la comunidad: de la primera se encarga el Estado, de la segunda el Mercado. Por eso la construcción de la territorialidad campesina agroalimentaria presupone una articulación entre producción, naturaleza, política y cultura campesina.

A diferencia de la gobernanza neoliberal, que tiene como punto de partida la privatización de la gestión ambiental, el Territorio Campesino Agroalimentario constituye un sistema de gobernanza que hunde sus raíces en los vínculos comunitarios. Ante el avance violento de la racionalidad extractivista, el fortalecimiento organizativo para la defensa y construcción de lo común, y la creación de estructuras legales e institucionales subalternas que estén

23 Una lectura articulada de Davies (2011) y Gray (2003, 2015) puede servir para comprender cómo los discursos de 'paz' y 'gobernanza' terminan funcionando más como mecanismos homogenizadores que neutralizan los procesos de cambio social. 
en capacidad de protegerlos, se convierten en un imperativo.

La construcción del TCA es una lucha por el reajuste de los sistemas productivos con los sistemas naturales ante al desajuste metabólico estructural causado por el modelo de desarrollo capitalista. Un primer escenario para llevar a cabo este reajuste es el local, donde se llevan a cabo luchas muy importantes por el reconocimiento del campesinado como sujeto político y por la implementación de un Plan de vida campesino. Ahora bien, Las soluciones tienen que trascender este escenario. Se requieren cambios también desde arriba ${ }^{24}$. La gobernanza no sólo se disputa a nivel local. Si esta quiere convertirse en un proceso emancipatorio debe confrontar la institucionalidad estatal en todos sus niveles, dentro y fuera de ella. No se trata de una lucha por el acceso libre de los recursos (del todo para todos) sino por la protección organizada de lo común (del todo para la comunidad).

Las formas de gobierno a escala local deben contar con el apoyo de instituciones comunales en el marco de una alianza, ya no público-privada, como actualmente se quiere, sino pública-comunitaria. Una alianza que permita generar instituciones sólidas que garanticen una organización ambiental del territorio respaldada por un Estado realmente funcional a los intereses populares y comunitarios, y a los reajustes metabólicos que se requieren para proteger el planeta.

La construcción de la territorialidad campesina agroalimentaria se basa en la articulación de producción, naturaleza, política y cultura campesina. En la misma vía de la proclama de los campesinos alemanes durante

\footnotetext{
${ }^{24}$ La disputa por el Estado siempre debe estar presente en el horizonte de acción de las luchas socioambientales. Véase Harvey (2011).
}

las guerras en el Sacro Imperio Germánico, "iOmnia sunt communia!", el TCA es un proceso de producción semiótico-material del territorio que se construye desde la recuperación política de lo común.

\section{LITERATURA CITADA}

Agencia Prensa Rural (13 de julio de 2017). "Macizo colombiano: entre la explotación minera y la lucha por los recursos hídricos". Recuperado de https://prensarural.org/spip/spip. php?article21766

Backer, L. (2012). "Governance without government: An overview". En G. Handl, J. Zekoll, y P. Zumbansen (Eds.), Beyond Territoriality: Transnational Legal Authority in an Age of Globalization, 87-123.

Bassols, M., y Mendoza, C. (Eds.). (2011). Gobernanza. Teoría y prácticas colectivas. Barcelona: Anthropos Editorial.

Bebbington, A. e Hinojosa, L. (2007). "Conclusiones: minería, neoliberalización y reterritorializaciónen el desarrollo rural". En A. Bebbington (Ed.), Minería, movimientos sociales y respuestas campesinas. Lima: IEP, CEPES.

Berggruen, N. y Gardels, N. (2013). Intelligent governance for the 21st century. Cambridge: Polity Press.

Beunen, R., Assche, K., y Duineveld, M. (Eds.). (2015). Evolutionary Governance Theory. New York: Springer.

Bolívar, A. (2016). "Líderes indígenas y campesinos asesinados en la antesala de la 'paz'". En Desde Abajo. Recuperado de: https://www.desdeabajo. info/colombia/item/29614-lideres-indigenas-ycampesinos-asesinados-en-la-antesala-de-lapaz.html

Brown, J. (2001). De la gobernanza o la constitución de la política del neoliberalismo. Recuperado el 25 de enero de 2018, de France.attac. org: https://france.attac.org/archives/spip.php? article3284

Castilla, A. (2016). "Proyecto de acto Legislativo. Cartilla pedagógica \& ABC del Proyecto". [Archivo personal].

Castro-Gómez, S. y Grosfoguel, R. (Eds.). (2007). El giro decolonial. Bogotá: El Siglo del Hombre Editores. 
Coordinador Nacional Agrario (CNA). (2015). "Territorios Agroalimentario". En Biodiversidad, No. 85. pp. 13-15.

Cruz. E. (2017). Caminando la palabra. Bogotá: Ediciones Desde Abajo.

Cruz, E. (2017a). "Justicia ambiental, justicia ecológica y diálogo intercultural". En Elementos (105), pp. 9-16.

Cuenca, T. (2017). "Los Territorios Campesinos Agroalimentarios, una apuesta por la construcción de paz desde los territorios". En Revista Cien Días (89), pp. 29-30.

Cumbre Agraria (11 de abril de 2014). "Pliego de peticiones de la cumbre agraria". Recuperado de: https://www.cumbreagraria.org/1-tierras-territorios-colectivos-y-ordenamiento-territorial/

Davies, J. (2011). Challenging Governance Theory: from network to hegemony. Bristol: The Policy Press.

Davies, J. (2014a). "Contesting governance hegemonies: Developments in critical theory and practice Part 1". Critical Policy Studies, 8(1), 1-4. https://doi.org/10.1080/19460171.2014.883853

Davies, J. (2014b). "Contesting governance hegemonies: Developments in critical theory and practice, Part 2". Critical Policy Studies, 8(2), 129-132.

https://doi.org/10.1080/19460171.2014.909200

De Castro, F., Hogenboom, B., y Baud, M. (2015). Gobernanza ambiental en América Latina. Buenos Aires: Clacso.

de Sousa Santos, B., y Garavito, C. A. R. (Eds.). (2007). El derecho y la globalización desde abajo Hacia una legalidad cosmopolita. Barcelona: Anthropos Editorial.

Departamento Nacional de Planeación (DNP). (2014). Plan Nacional de Desarrollo 2014-2018: Todos por un nuevo país. Congreso de la República de Colombia. Ley 1753 de 2015.

Departamento Nacional de Planeación (DNP). (2018). CONPES 3915: Lineamientos de política y estrategias para el desarrollo regional sostenible del Macizo colombiano. Bogotá.

Dominguez, R. (2015). "Environmental governance in the EU-Latin American relationship". Regions and Cohesions, 5(3), 63-82.

Drobot, G. A. (2010). The Issue of Global Governance in the Context of International Relations Theory. Globalistics and Globalization Studies 300-308, 300-308. Recuperado de http://www. sociostudies.org/books/files/globalistics_and_ globalization_studies/300-308.pdf.
Duarte, C. (2017). "Los Territorios Campesinos Agroalimentarios". En lasillavacia.com. Recuperado de http://lasillavacia.com/silla-llena/redrural/historia/los-territorios-campesinos-agroalimentarios-59671

Duffield, M. (2001). Global governance and the new wars. London: Zed Books.

European Commission (2014). "Promoting good governance - European Social Fund thematic paper". Publications Office of the European Union.

Feierstein, D. (2014). Genocide as Social Practice. New Brunswick: Rutgers University Press.

Foucault, M. (2007). Nacimiento de la biopolítica. Buenos Aires: Fondo de Cultura Económica.

Foucault, M. (2006). Seguridad, Territorio y Población. Buenos Aires: Fondo de Cultura Económica.

Gabriel, N. (2014). "Urban Political Ecology: Environmental Imaginary, Governance, and the NonHuman". Geography Compass, 8(1), 38-48.

Garay, L. (Dir.). (2014). Minería en Colombia. Contraloría General de la Nación.

García, M. (2017). "Una mirada a la trayectoria de las luchas sociales en tres subregiones nariñenses - Informes DHESCA". Fundación Humanismo y Democracia $H+D$, la Fundación FUNDESUMA/CIMA Nariño, y el Centro de Investigación y Educación Popular/Programa por la Paz.

Gaudin, J-P. (2002). Pourquoi la gouvernance? Paris: Presses de Sciences-Po.

Granados, D. y Houghton, J. (2017). "De lo políticocomunitario a lo político-institucional: Reflexiones sobre experiencias electorales de los procesos comunitarios en el Cauca". Bogotá: CDPAZ-PLANETA PAZ.

Granados, D. y Houghton, J. (2017). "De lo político-comunitario a lo político-institucional: Reflexiones sobre experiencias electorales de los procesos comunitarios en el Cauca". Bogotá: CDPAZ-PLANETA PAZ.

Gray, J. (2003). Straw dogs. New York: Farrar, Straus and Giroux.

Gray, J. (2015). John Gray: Steven Pinker is wrong about violence and war. Theguardian.Com. Recuperado de https://www.theguardian.com/ books/2015/mar/13/john-gray-steven-pinkerwrong-violence-war-declining 
Guhl Nannetti, E., y Leyva, P. (2015). La gestión ambiental en Colombia, 1994-2014. Bogotá D.C.: FESCOL.

Harvey, D. (2011). "The Future of the Commons". Radical History Review, (109), 101-107. https://doi.org/10.1215/01636545-2010-017

Harvey, D. (2014). Diecisiete contradicciones y el fin del capitalismo. Madrid: Traficantes de Sueños.

Hogenboom, B., Baud, M., \& De Castro, F. (2012). Gobernanza Ambiental en América Latina: hacia una agenda de investigación integradora. 14(90), 78-88.

Instituto Geográfico Agustín Codazzi (IGAC). (2015). "Macizo colombiano se desangra: en los últimos 20 años ha perdido cerca de 500 mil hectáreas de bosques". Recuperado de https://igac. gov.co/noticias/macizo-colombiano-se-desangra-en-los-ultimos-20-anos-ha-perdido-cercade-500-mil-hectareas

International Monetary Fund (IMF). (1997). "Good Governance, the IMF's Role". Publication Services, Washington.

Jessop, B. (2016). The state: past, present, future. Cambridge: Polity Press.

Jiménez, A. (2008). Democracia y Neoliberalismo. Medellín: La Carreta Editores.

Klein, N. (2015). Esto lo cambia todo (Trad. Albino Santos Mosquera). Barcelona: Paidós.

Kooiman, J. (2005). "Gobernar en gobernanza". En La gobernanza hoy: 10 textos de referencia. Catalunya: Estudios Goberna.

Lateef, K. (2016). "Evolution of the World Bank's thinking on governance". Background Paper, Washington.

Laval, C., y Dardot, P. (2015). La nueva razón del mundo. Barcelona: Gedisa Editorial.

Leff, E. (2003). "La ecología política en América Latina: un campo en construcción". Sociedad e Es-tado, 18, 17-40.

http://dx.doi.org/10.1590/S0102-69922003000100003

Macías, W. (2016). "Configuración, dinámica y elementos del Marco Cognitivo Agroambiental del Comité de Integración del Macizo Colombiano - CIMA". Universidad del Valle: Tesis de Maestría.

Mantilla, A. (2012). Estas locomotoras necesitan frenos. Entre los espacios basura y el mandato popular. Bogotá: CED-INS.
Mantilla, A. (2017). "La hipótesis del Estado corporativo". En Palabras al Margen edición No. 100. Recuperado de: http://palabrasalmargen.com/ edicion-100/la-hipotesis-del-estado-corporativo/

Marx, C. (2014). El capital. México, D.F.: Fondo de Cultura Económica.

Mattei, H. (2013). Bienes Comunes. Un Manifiesto. Madrid: Trotta.

Mejía, M. (Coord.). (2017). Agenda Común para la Paz desde los Territorios. Planeta Paz y Oxfam.

Monedero, J. (2003). "La trampa de la gobernanza: nuevas formas de participación política". Plataforma 2015 y Más, 76-86.

Monedero, J. (2008). Disfraces del Leviatán. Caracas: Centro Internacional Miranda.

Noguera, P. (2004). El reencantamiento del mundo. México, D.F.: PNUMA.

O'Connor, J. (1991). "On the two contradictions of capitalism". CNS, 2(3), 107-109.

Ostrom, E. (2011). El gobierno de los bienes comunes (Trad. de Leticia Merino Pérez). México, D.F.: Universidad Autónoma de México y Fondo de Cultura Económica.

Portillo, A. (2016). "Comunalidad y Geopolítica de la Resistencia". En Fermentun (26), pp. 168-172.

Rincón, J. (2012). "Una mirada al discurso del desarrollo". En Revista Académica e Institucional, Arquetipo (4), pp. 61-70.

Red de Solidaridad y Hermandad con Colombia (REDHER) (5 de diciembre de 2011). "Denuncia pública a la empresa Gran Colombia Gold de los municipios de Arboleda y San Lorenzo". Recuperado de http://www.redcolombia.org/index.php/regiones/ sur-occidente/narino/1660-denuncia-pca-a-la-empresa-gran-colombia-gold-de-los-municipios-dearboleda-y-san-lorenzo.html.

Rhodes, R. A. W. (2017). Network governance and the differentiated polity. Oxford: Oxford University Press.

Richards, B. (2007). Emotional Governance. New York: Palgrave Macmillan.

Riechmann, J. (2011). Tiempo para la vida. Bogotá: Bolsillo de Duende.

Rincón, J. (2012). "Una mirada al discurso del desarrollo". Revista Académica e Institucional, Arquetipo (4), 61-70. 
Rincón, J. (Ed.). (2017a). Crecer como un río Vol.2. Jornaliando cuesta arriba por vida digna, integración regional y desarrollo propio del Macizo Colombiano, Cauca, Nariño y Colombia (Vol.2). Bogotá D.C.: CNMH-CIMA-FUNDESUMA.

Robbins, P., \& Luginbuhl, A. (2007). "The last enclosure: Resisting privatization of wildlife in the western United States". Neoliberal Environments: False Promises and Unnatural Consequences, 5752(May), 25-37.

Rueda, D. (2012). "Gobernanza y subpolítica en la teoría política crítica de Boaventura de Sousa Santos". Perspectivas Rurales. Nueva Época, 11(21), 1409-325.

Sampson, G. (Ed.). (2008). The WTO and global governance: Future directions. Tokyo: United Nations University Press.

Schuler, G. (2008). "Effective Governance through Decentralized Soft Implementation: The OECD Guidelines for Multinational Enterprises". German Law Journal, 9(11), 1753-1778.

Stoker, G. (2019). "Governance as theory: five propositions". International Social Science Journal,
68(227-228), 15-24.

https://doi.org/10.1111/issj.12189

Svampa, M. (2012). "Extractivismo neodesarrollista y movimientos sociales. ¿Un giro ecoterritorial hacia nuevas alternativas?". En Más allá del desarrollo. Lang, M. y Mokrani, D. (Compiladora). Quito: Fundación Rosa Luxemburg/Abya Yala.

Szalkowicz, G., \& Solana, P. (Eds.). (2017). América Latina. Huellas y retos del ciclo progresista. Bogotá: La Fogata Editorial.

United Nations (2014). "Global governance and global rules for development in the post-2015 era". Sales No. E.14.II.A.1

Vásquez, D. (2017). "Conflictos territoriales y derechos al territorio y al agua en el Macizo andino nariñense - Informes DHESCA". Fundación Humanismo y Democracia $\mathrm{H}+\mathrm{D}$, la Fundación FUNDESUMA/CIMA Nariño, y el Centro de Investigación y Educación Popular/Programa por la Paz.

Weston, B., y Bollier, D. (2013). Green Governance ecological. Cambridge: Cambridge University Press. 